\title{
Adult gaucher disease in southern Tunisia: report of three cases
}

\author{
Faten Ben Rhouma ${ }^{1,2}$, Faten Kallel ${ }^{3}$, Rym Kefi ${ }^{1}$, Wafa Cherif ${ }^{1}$, Majdi Nagara', Hela Azaiez ${ }^{1}$, Ines Jedidi, \\ Moez Elloumi ${ }^{3}$, Sonia Abdelhak ${ }^{1 *}$ and Sondes Mseddi ${ }^{3}$
}

\begin{abstract}
Background: Gaucher disease (GD) is the most frequent lysosomal storage disorder; type 1 is by far the most common form. It is characterized by variability in age of onset, clinical signs and progression. It is usually diagnosed in the first or second decade of life with the appearance of bone pains, splenomegaly and thrombocytopenia, but the disease may be diagnosed at any age between 1 and 73 years. In the present study, we report 3 cases with late onset of GD in whom the disease was a surprise finding including one patient with Parkinson disease. This late onset is described as an adult form of Gaucher disease.

Findings: Molecular investigation showed mutational homogeneity in Tunisian adult patients suffering from GD. Indeed, all patients carry the p.N370S mutation: two patients at a homozygous state and one patient at compound heterozygous state.

Conclusion: The p.N370S mutation presents a large variability in the onset of the disease and its clinical manifestation supporting the view that GD should be considered as a continuum phenotype rather than a predefined classification.
\end{abstract}

Virtual Slides: The virtual slide(s) for this article can be found here: http://www.diagnosticpathology.diagnomx.eu/ vs/1701276661617840.

Keywords: Adult, Gaucher disease, p.N370S, Parkinsson disease, Tunisia

\section{Findings}

Gaucher disease (GD) is the most frequent lysosomal storage disorder [1]. It is an autosomal recessive inborn defect in the glucocerebrosidase gene $(G B A)$ on1q21 leading to enzymatic deficiency of the $\beta$-glucocerebrosidase and the accumulation of glycosylceramide substrate in the macrophage's lysosomes. GD is characterized by a considerable phenotypic and genotypic heterogeneity [2]. There is a wide range of clinical manifestationsfrom nearly asymptomatic patients who have mild bone pain up to full spectrum of severe complications with cytopenia, hepatosplenomegaly and pathologic fractures [3]. More than 200 mutations were identified along GBA gene http://www.hgmd.org. In previous studies, investigation of GD showed that p.N370S, p.L444P and

\footnotetext{
*Correspondence: sonia.abdelhak@pasteur.rns.tn

${ }^{1}$ Molecular Investigation of Genetic Orphan Diseases, Pasteur Institute, Tunis - Tunisia Full list of author information is available at the end of the article
}

RecNciI mutations were relatively frequent in Tunisian patients $[4,5]$. In the present study, we report three Tunisian adult GD patients including one patient with Parkinson disease in whom the disease was incidentally found following bone marrow examination during check up for thrombocytopenia with splenomegaly. These cases were investigated for the p.N370S, p.L444P and RecNcil mutations in GBA gene.

Three patients diagnosed with GD from three unrelated families from southern Tunisia were investigated. The diagnosis was based on the occurrence of hepatosplenomegaly associated with hematological abnormalities and/or bone lesions and was confirmed in all patients by the presence of Gaucher cells.

After the patient's written informed consent, $5 \mathrm{ml}$ of blood were collected. DNA was extracted from peripheral blood mononuclear cells using the standard saltingout procedure. DNA samples were then amplified by polymerase-chain-reaction (PCR) followed by enzymatic
C Biomed Central 
restriction using $X h o \mathrm{I}$ and NciI to screen for p.N370S and p.L444P respectively. Sequencing was performed on an ABI 3130 to detect the three mutations (p.N370S, p. L444P and RecNcil).

\section{Case 1}

A 46 years old male was referred to the hematology departement of Sfax in Southern Tunisia for thrombocytopenia (platelet $20000 / \mathrm{mm}^{3}$ ). Clinical examination showed a voluminous splenomegaly associated with pancytopenia. Neurological symptoms were absent. The diagnosis of GD was confirmed by bone marrow examination (Figure 1: A1, A2). The patient underwent partial splenectomy. Spleen and liver histology showed Gaucher cells infiltration. The patient did not follow any specific enzymotherapy. At the age of 51, he started suffering from pain in his left leg with a complete functional impairment. Radiological investigations of the leg showed an Erlenmeyer flask deformity and cortical fracture requiring surgical treatment. A bone biopsy was performed and revealed the presence of Gaucher cells. The patient was treated with a cast immobilization and an antalgic symptomatic treatment. The treatment

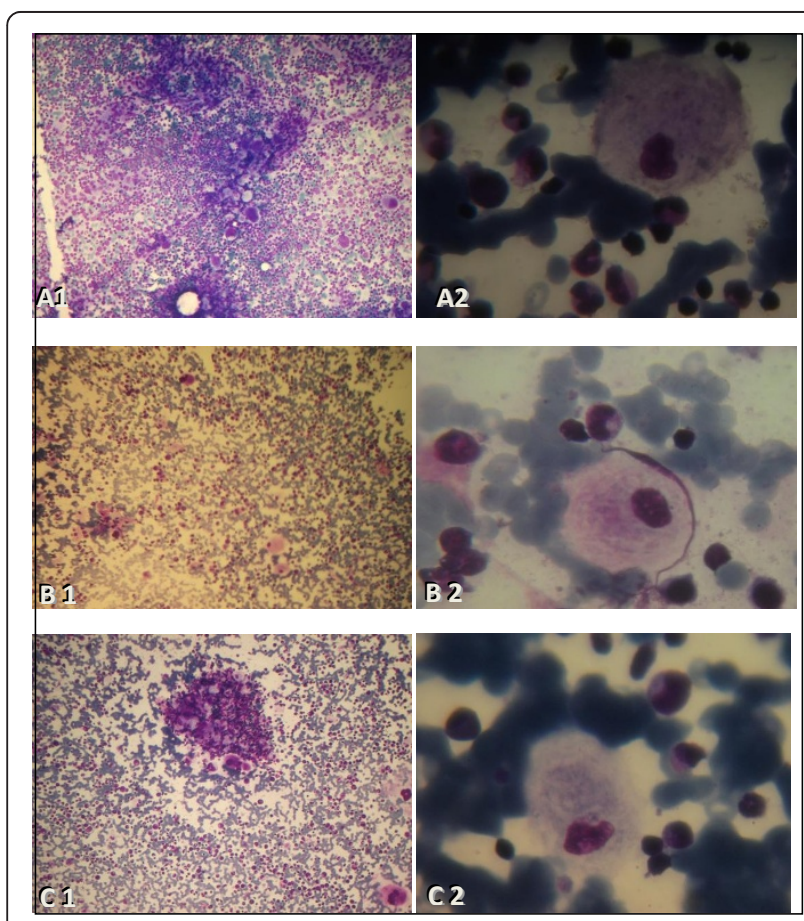

Figure 1 Micorscopic images of Gaucher cells of the three studied GD patients: A cell with a "sandpaper" appearance was evident. A: Myelogram of Case 1: microscopic image of Gaucher cells (A1: MGG, X10) and (A2: MGG, X100). B: Myelogram of case 2: microscopic image of Gaucher cells (B1: MGG, X10) and (B2: MGG, X100). C: Myelogram of Case 3: microscopic image of Gaucher cells (C1: MGG, X10) and (C2: MGG, X100). Abbreviation: MGG; MayGrünwald Giemsa. outcome showed a limited effectiveness, with no consolidation and persistence of bone pain. An osteosynthesis by external fixator was then performed. The patient developed Parkinson disease presented with ataxia, rigidity and tremor at the age of 52. Family history was negative for GD although one brother suffered from Schizophrenia. Screening of exons 9 and 10 of GBA gene revealed that the patient was compound heterozygous for the p.N370S and RecNciI mutations.

\section{Case 2}

A 35 years old female was referred to the hematology departement of Sfax with thrombocytopenia (platelet count $100000 / \mathrm{mm}^{3}$ ). Family history showed no particular pathologies. The diagnosis of GD was confirmed by a myelogram and bone marrow biopsy that revealed the presence of Gaucher cells (Figure 1: B1, B2). Subsequently, biochemical analysis of $\beta$-glucocerebrosidase activity in leucocytes confirmed enzyme deficiency. Neurological and osteoarticular examination were normal. Molecular genetic testing for the three common Gaucher mutations revealedhomozygosity for the p.N370S mutation. The patient being monitored regularly and is undergoing a therapeutic trial with a substrate reduction therapy initiated on April 2011.

\section{Case 3}

The patient is a 34 year-old female from a consanguineous family. Her mother has developed uterine fibroid, two sisters had cholecystectomy and one brother had a bone disease. Her husband and her two children are in a good health. Her initial clinical presentation was an unexplained bicytopenia (white blood cells of $2905 / \mathrm{mm}^{3}$ and platelet count $130000 / \mathrm{mm}^{3}$ ) and splenomegaly. The diagnosis of GD was confirmed by myelogram (Figure 1: C1, C2). Spleen histology showed Gaucher cells. Molecular analysis including PCR/RFLP and DNA sequencing identified the p.N370S mutation at the homozygous state. The patient underwent a partial splenectomy and the outcome showed improvement of pancytopenia.

\section{Discussion}

To the best of our knowledge this is the second report describing adult patients with GD in Tunisia and the first report of an association of GD and Parkinson disease in our Country. The first report by Dandana et al [6] described a 50 year old patient with GD without any neurological disorder. Many adult cases with GD have been reported worldwide. Based on data from the Gaucher Registry (ICGG 2008) the p.N370S mutation was found in 53\% of all GD patients and represents the highest prevalence. About 14\% of GD patients were diagnosed between the age of 31 to 50 year old [7]. 
Table 1 Clinical and genetic features of 3 Tunisian GD patients.

\begin{tabular}{|c|c|c|c|c|c|c|c|c|c|}
\hline \multirow[t]{2}{*}{ Patients } & \multirow[t]{2}{*}{ Sexe } & \multirow[t]{2}{*}{ Consanguinity } & \multicolumn{6}{|c|}{ Clinical findings } & \multirow[t]{2}{*}{ Genetic status } \\
\hline & & & Onset age (year) & $H M G$ & SMG & Platelet level & Neurological symptoms & $\begin{array}{l}\text { Osteoarticular } \\
\text { symptoms }\end{array}$ & \\
\hline Case 1 & $M$ & No & 46 & - & + & $20000 / \mathrm{mm}^{3}$ & + & + & N370S/RecNcil \\
\hline Case 2 & $\mathrm{~F}$ & Yes & 35 & - & + & $100000 / \mathrm{mm}^{3}$ & - & - & N370S/N370S \\
\hline Case 3 & $\mathrm{~F}$ & Yes & 34 & - & + & $130000 / \mathrm{mm}^{3}$ & - & - & N370S/N370S \\
\hline
\end{tabular}

Abbreviations: HMG, hepatomegaly; SMG, splenomegaly; M, male; F, female

Among the patients we report here, two patients were homozygous for the p.N370S mutation (table 1). Homozygosity for this mutation appears common among GD type I adult patients [8]. So far, this mutation was found in $44 \%$ of paediatric Tunisian patients with GD [5]. Unlike most of the autosomal recessive genetic diseases in Tunisia for which the majority of the patients is born to consanguineous marriages and is homozygous for deleterious alleles, the p.N370S mutation is encountered at heterozygous state in combination with other mutated alleles [5].

One patient (case 1) developed Parkinson disease at age 52. The co-morbidity of GD and Parkinson disease has been largely discussed [9-11]. The incidence of Parkinson disease seems particularly high among patients with GD; Bembi and collaborators found four Parkinson patients (6.9\%) among 58 patients with GD [12]. Lachmann and Platt found 3 cases of Parkinson disease in 130 patients (2.3\%) [13]. The first signs of Parkinson disease appear at an earlier age in patients with GD compared to the general population: 48 versus 71 years average age, respectively [14]. It has been increasingly recognized that Parkinsonism may be a clinical feature of GD type I and may even precede its diagnosis [15]. In addition, heterozygosity for certain $G B A$ gene mutations predisposes to a higher risk for Parkinson disease according to Chérin and collaborators [16]. Whereas, a recent study presented by Nishioka and collaborators on 395 patients with Parkinson disease and 372 control subjects did not show a statistically significant association with p.K26R, p.K186R and p.N370S in the Tunisian population $(\mathrm{P}>0.05)$ [11]. The p.N370S mutation was identified in only one sporadic patient with Parkinson disease and 3 control subjects indicating that the frequency of this mutation in Tunisian patients is much lower than that observed in Ashkenazi Jews patients with Parkinson disease (31\%).Furthermore, Spitz and collaborators reported that most patients with GD never develop Parkinson disease, suggesting the involvement of other genetic and/or environmental factors in the GD process [15].

It has been suggested that only one third of the patients who were homozygote for p.N370S mutation come to medical attention and that about two thirds remain asymptomatic throughout life [17]. Carrier screening programs may lead to the identification of asymptomatic cases. In the literature, carrier screening and termination of pregnancy of GD is controversial, in particular for mild mutations like the p.N370S mutation $[18,19]$. In Tunisia, GD like other autosomal recessive disorders $[20,21]$, is rare and does not represent a major public health concern. We suggest that prenatal diagnosis for couples at risk carrying a severe mutation (L444P, RecNciI) is the best alternative to reduce the incidence of the severe form of the disease.

There is a great variability in the clinical manifestation as well as in the onset and course of GD. This supports the need for a new classification and reinforces the hypothesis of the concept of a phenotypic continuum. Clinicians, especially in hematology and internal medicine, should suspect the diagnosis of GD in any adult patient suffering from abdominal and/or bone pain with unexplained hematological disorder especially in combination with organomegaly.

\section{Abbreviations}

GD: Gaucher disease; PCR: polymerase chain reaction; PD: Parkinson disease; RFLP: Restriction fragment length polymorphism.

\section{Acknowledgements}

We grateful acknowledge the patients and their families for participation in this study.

\section{Author details}

${ }^{1}$ Molecular Investigation of Genetic Orphan Diseases, Pasteur Institute, Tunis - Tunisia. ${ }^{2}$ Child Neurological diseases Unit, Faculty of Medicine, TunisTunisia. ${ }^{3}$ Hematology Department, Hedi Chaker Hospital, Sfax- Tunisia.

\section{Authors' contributions}

SA had full access to all the data in the study and takes responsibility for the integrity of the data and the accuracy of the data analysis. Study concept and design: SA and SM. Acquisition of data: FBR, FK, RK, WC, MN, HA, IJ and ME. Analysis and interpretation of data: FBR, RK, WC, MN, HA, SA and SM. Drafting the manuscript: FBR. Critical revision of the manuscript for important intellectual content: SA, RK, HA, SM. Obtained funding: SA. Administrative, technical or material support: FBR, RK, WC, MN, and HA. Study supervision: SA, ME and SM. All authors read and approved the final manuscript.

\section{Competing interests}

The authors declare that they have no competing interests.

Received: 12 October 2011 Accepted: 10 January 2012 Published: 10 January 2012 
References

1. Meikle PJ, Hopwood JJ, Clague AE, Carey WF: Prevalence of lysosomal storage disorders. JAMA 1999, 281:249-254.

2. Sidransky E: Gaucher disease: complexity in a "simple" disorder. Mol Genet Metab 2004, 83:6-15.

3. Neudorfer $\mathrm{O}$, Giladi N, Elstein D, Abrahamov A, Turezkite T, Aghai E, Reches A, Bembi B, Zimran A: Occurrence of Parkinson's syndrome in type I Gaucher disease. Q J M 1996, 89:691-694.

4. Cherif W, Ben Turkia H, Tebib N, Amaral O, Ben Rhouma F, Abdelmoula MS, Azzouz H, Caillaud C, Sà Miranda MC, Abdelhak S, Ben Dridi MF: Mutation spectrum of Gaucher disease in Tunisia: high frequency of N370S/ RecNcil compound heterozygous. Arch Inst Pasteur Tunis 2007, 84:65-70.

5. Cherif W, Ben Turkia H, Ben Rhouma F, Riahi I, Chemli J, Kefi R, Messai H, Amaral O, Sá Miranda MC, Caillaud C, Tebib N, Ben Dridi MF, Abdelhak S: Gaucher disease in Tunisia: High frequency of the most common mutations. Blood Cells Mol Dis 2009, 43:161-162.

6. Dandana A, Ferchichi S, Khedhiri S, Chkioua L, Jaidane Z, Monastiri K, Ben Khelifa S, Ben Mansour R, Maire I, Froissart R, Bonnet V, Laradi S, Miled A: Biochemical and molecular diagnosis of Gaucher disease in Tunisia. Ann Biol Clin (Paris) 2007, 65:647-652.

7. Fairley C, Zimran A, Phillips M, Cizmarik M, Yee J, Weinreb N, Packman S: Phenotypic heterogeneity of N370S homozygotes with type I Gaucher disease: an analysis of 798 patients from the ICGG Gaucher Registry. J Inherit Metab Dis 2008, 31:738-744.

8. Zimran A, Gelbart T, Westwood B, Grabowski G, Beutler E: High frequency of the Gaucher disease mutation at nucleotide 1226 among Ashkenazi Jews. Am J Hum Genet 1991, 49:855-859.

9. Capablo JL, Saenz de Cabezón A, Fraile J, Alfonso P, Pocovi M, Giraldo P: Spanish Group on Gaucher Disease, Neurological evaluation of patients with Gaucher disease diagnosed as type 1. J Neurol Neurosurg Psychiatry 2008, 79:219-222.

10. Goker-Alpan O, Lopez G, Vithayathil J, Davis J, Hallett M, Sidransky E: The spectrum of Parkinsonian manifestations associated with glucocerebrosidase mutations. Arch Neurol 2008, 65:1353-1357.

11. Nishioka K, Vilariño-Güell C, Cobb SA, Kachergus JM, Ross OA, Wider C, Gibson RA, Hentati F, Farrer MJ: Glucocerebrosidase mutations are not a common risk factor for Parkinson disease in North Africa. Neurosci Lett 2010, 477:57-60.

12. Bembi B, Zambito Marsala S, Sidransky E, Ciana G, Carrozzi M, Zorzon M, Martini C, Gioulis M, Pittis MG, Capus L: Gaucher's disease with Parkinson's disease: clinical and pathological aspects. Neurology 2003, 61:99-101.

13. Lachmann RH, Platt FM: Substrate reduction therapy for glycosphingolipid storage disorders. Expert Opin Investig Drugs 2001, 10:455-466.

14. Elbaz A, Bower JH, Peterson BJ, Maraganore DM, McDonnell SK, Ahlskog JE, Schaid DJ, Rocca WA: Survival study of Parkinson disease in Olmsted County, Minnesota. Arch Neurol 2003, 60:91-96.

15. Spitz M, Rozenberg R, Silveira PA, Barbosa ER: Parkinsonism in type 1 Gaucher's disease. J Neurol Neurosurg Psychiatry 2006, 77:709-710.

16. Chérin P, Sedel F, Mignot C, Schupbach M, Gourfinkel-An I, Verny M, Baumann N: Neurological manifestations of type 1 Gaucher's disease: Is a revision of disease classification needed? Rev Neurol (Paris) 2006 162:1076-1083.

17. Balwani M, Fuerstman L, Kornreich R, Edelmann L, Desnick RJ: Type 1 Gaucher disease: significant disease manifestations in "asymptomatic" homozygotes. Arch Intern Med 2010, 170:1463-1469.

18. Zuckerman S, Lahad A, Shmueli A, Zimran A, Peleg L, Orr-Urtreger A, LevyLahad E, Sagi M: Carrier screening for Gaucher disease: lessons for lowpenetrance, treatable diseases. JAMA 2007, 298:1281-1290.

19. Beutler E: Carrier screening for Gaucher disease: more harm than good? JAMA 2007, 298:1329-1331.

20. Chkioua L, Khedhiri S, Ben Turkia H, Chahed H, Ferchichi S, Ben Dridi MF, Laradi S, Miled A: Hurler disease (Mucopolysaccharidosis type $\mathrm{IH}$ ): clinical features and consanguinity in Tunisian population. Diagn Pathol 2011, 6:113.

21. Chkioua L, Khedhiri S, Kassab A, Bibi A, Ferchichi S, Froissart R, VianeySaban C, Laradi S, Miled A: Molecular analysis of mucopolysaccharidosis type I in Tunisia: identification of novel mutation and eight novel polymorphisms. Diagn Pathol 2011, 6:39-46. doi:10.1186/1746-1596-7-4

Cite this article as: Ben Rhouma et al: Adult gaucher disease in

southern Tunisia: report of three cases. Diagnostic Pathology 2012 7:4.

\section{Submit your next manuscript to BioMed Central and take full advantage of:}

- Convenient online submission

- Thorough peer review

- No space constraints or color figure charges

- Immediate publication on acceptance

- Inclusion in PubMed, CAS, Scopus and Google Scholar

- Research which is freely available for redistribution 